\title{
Evaluation of the Total Design Method in a survey of Japanese dentists

\author{
Yukie Nakai ${ }^{\dagger 1}$, Peter Milgrom ${ }^{\dagger 2}$, Toshiko Yoshida ${ }^{\dagger 1}$, Chikako Ishihara ${ }^{\dagger 1}$ and \\ Tsutomu Shimono*1
}

\begin{abstract}
Address: ${ }^{1}$ Department of Behavioral Pediatric Dentistry, Okayama University Graduate School of Medicine, Dentistry and Pharmaceutical Sciences, Okayama, Japan and ${ }^{2}$ Department of Dental Public Heath Sciences, University of Washington, Seattle, USA

Email: Yukie Nakai - yukien@md.okayama-u.ac.jp; Peter Milgrom - dfrc@u.washington.edu; Toshiko Yoshida - toshiko@md.okayama-u.ac.jp; Chikako Ishihara - dechika21@ hotmail.com; Tsutomu Shimono* - shimono@md.okayama-u.ac.jp

* Corresponding author †Equal contributors
\end{abstract}

Published: 23 August 2005

BMC Medical Research Methodology 2005, 5:27 doi:10.1 186/147I-2288-5-

27

This article is available from: http://www.biomedcentral.com/I47I-2288/5/27

(c) 2005 Nakai et al; licensee BioMed Central Ltd.

This is an Open Access article distributed under the terms of the Creative Commons Attribution License (http://creativecommons.org/licenses/by/2.0), which permits unrestricted use, distribution, and reproduction in any medium, provided the original work is properly cited.

\begin{abstract}
Background: This study assessed the application of the Total Design Method (TDM) in a mail survey of Japanese dentists. The TDM was chosen because survey response rates in Japan are unacceptably low and the TDM had previously been used in a general population survey.

Methods: Four hundred and seventy eight dentist members of the Okayama Medical and Dental Practitioner's Association were surveyed. The nine-page, 27-item questionnaire covered dentist job satisfaction, physical practice, and dentist and patient characteristics. Respondents to the first mailing or the one-week follow-up postcard were defined as early responders; others who responded were late responders. Responder bias was assessed by examining age, gender and training.

Results: The overall response rate was $46.7 \%$ (223/478). The response rates by follow-up mailing were, $18 \%$ after the first mailing, $35.4 \%$ after the follow-up postcard, $42.3 \%$ after the second mailing, and $46.7 \%$ after the third mailing. Respondents did not differ from non-respondents in age or gender, nor were there differences between early and late responders.

Conclusion: The application of TDM in this survey of Japanese dentists produced lower rates of response than expected from previous Japanese and US studies.
\end{abstract}

\section{Background}

Mail survey questionnaires of dentists as well as the general public have been used widely in the U.S. and response rates are generally high. In contrast the use of mail surveys in Japan has been less successful. Japanese textbooks on social science research techniques report return rates of no more than $20-40 \%$ [1-3]. A mail survey conducted by one of the local Japanese dental associations had a response rate of $10 \%$ (unpublished data). Mail surveys reported in the Japanese medical literature had response rates ranging from 49 to $90 \%$ [4-8]. Research subjects in the various studies were the physicians and residents working at two private University hospitals (Response rate 49.1\%) [4], the institutions belonging to an oncology group (Response rate 90.2\%) [5], the council members of the Japanese society of child neurology (Response rate 


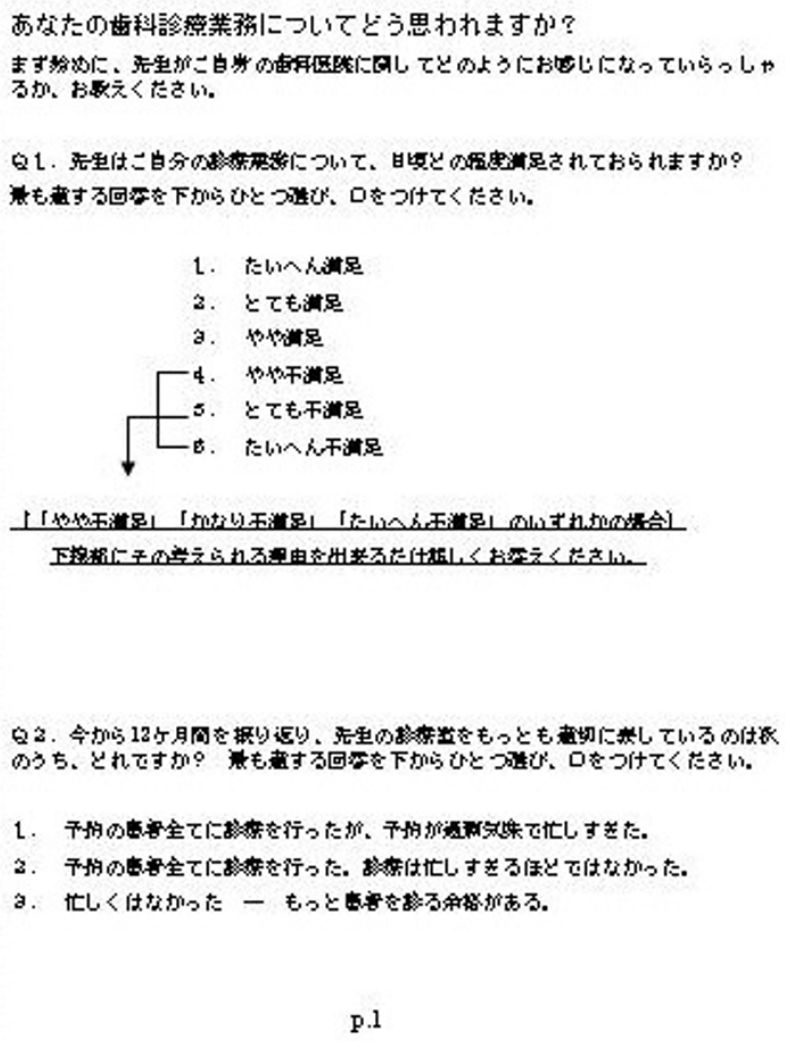

Figure I

The first page of the questionnaire and its English translation.

\section{HOW WOULD YOU FEEL ABOUT YOUR PRACTICE}

First, we uould like you to tell us how you foel about your practioe.

Q1. Usually how atiatied are you with your practice? (Circle the best arvier)

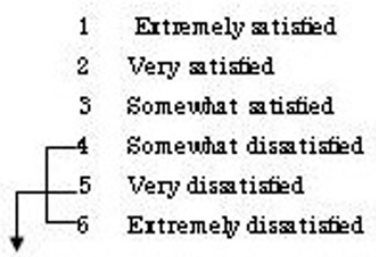

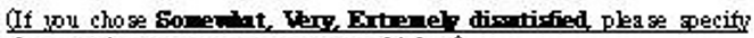
the mos important rea an wou can thirk of

Q2. Wiich of the folbuing bes describes your practice during the past 12 months? (Circle the bes ansuer)

1. Provided care to all uto reque sted treatments but the practioe uas overuorked

2. Provided care to all uto requested treatments ard the practioe us s not overuorked

3. Sot bua enough-the practice could have treated more patients

p.1
72.8\%) [6], ophthalmologists in hospitals and clinics (Response rate 73\%) [7], and psychologists (Response rate not given) [8]. However, the publications lack methodological detail. Only two of the five, for example, provide the source of the mailing lists. In two of the surveys, questionnaires were sent to a representative at each hospital or institution rather than to individuals directly $[4,5]$. None of the five papers indicated whether the studies were sponsored by a professional association, or university or other group. One of five publications indicated that an advance letter was sent before the questionnaire [7]. Only one paper specified whether participants were told how the data would be used [7]. None of the papers explained whether an incentive was included in the mailing of the questionnaire. Other details generally missing were the length of the questionnaire (missing in 2/5) $[4,6,8]$, telephone contacts for more information (missing in all 5) or assurance of confidentiality (missing in all 5).
The Total Design Method (TDM), which was developed by Dillman and includes personalization of the cover letter and repeated follow-ups, was designed to achieve high response rates and minimize the potential influence of systemic nonresponse bias [9]. The response rate generally is lower in surveys of the general public and higher in surveys of professionals although this varies by group and subject. Locker and colleagues reported a $71.6 \%$ response rate when an oral health questionnaire using the TDM was used to survey the general population from voters' lists [10]. Fiset and colleagues mailed questionnaires concerning dental malpractice claims to dentists using the TDM, and reported a $69.6 \%$ response rate [11].

In the only application of the TDM in Japan to date, Jussaume and colleagues reported a $55.6 \%$ response rate for a survey of the general population on the subject of 748 when those surveyed were selected from telephone listings [12]. 


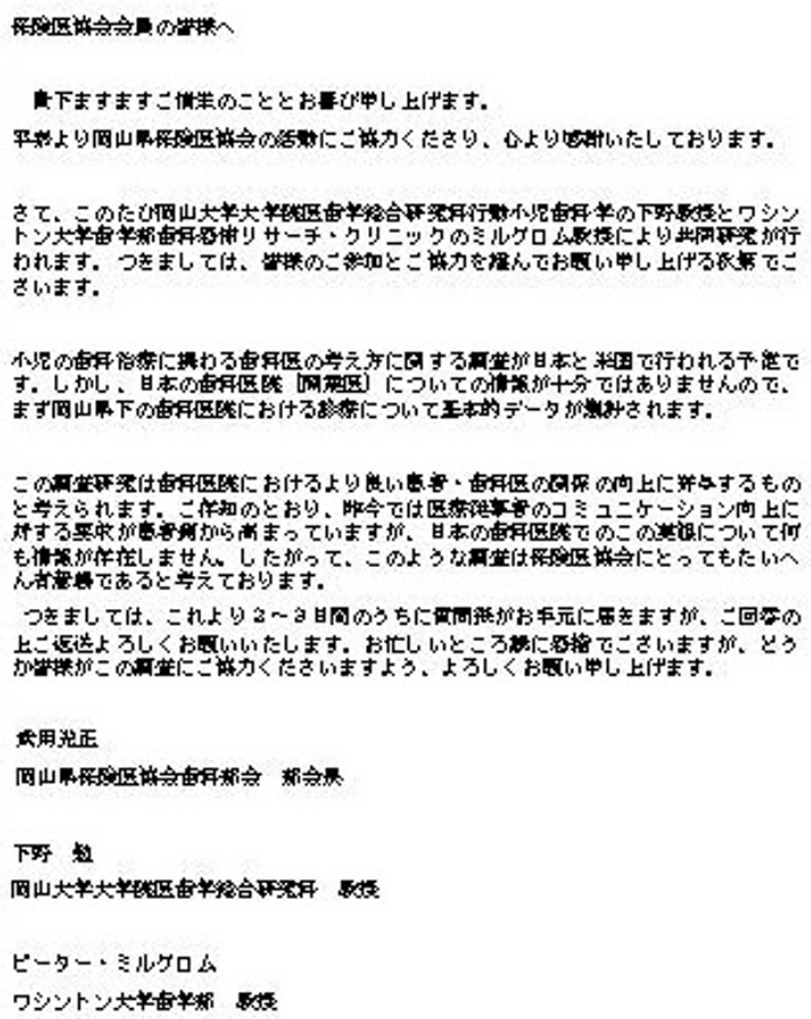

Dear member $x_{\text {, }}$

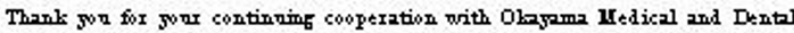
Practitioner's Boodiztion actirities.

I wond like to incite son to participats in the collaborative rexearch with Dr. Shimono, 2 professor in Ohpoma Uriver sits Grad nate school of Irolicine and Dentists Beharioral Pediatric Dentists and Dr. Uilorom, a proftesor in University of Washington Dental Fear g Fisearch Climics.

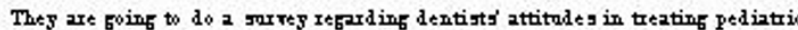
patienty both in Japan and the U.S. Bec2nse of their nufomiliarity with dentel practice in Japan, the $s$ are going to collect some de scriptive date of dentel practice

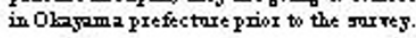

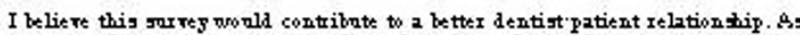
5on mas know, increasing nomber of patients desile better commonication betoreen health providerg and themselveg. Also there is no date arrilable 25 to what dental practice is like in Japan. Therefore, thig sur ves wond be of Ereat nive to the dertal associntion.

Within the next few d 25y, jon will receive 2 reque st to complete a que stionasire. I

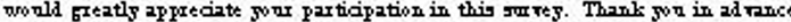
son cooperation and con sileration.

Uitroman B nyon

The pre sident, Obyama Ifedical and Dentel Fractitioner' a Assciation

Trotomn Shimono

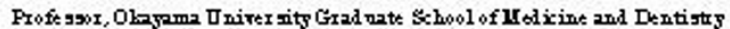

Peter Irilfrom

Froft s9or, Univerrity of Wizhington Shool of Dentists

Figure 2

Advance letter.

No work has been done on adapting the TDM to Japanese dental populations. The aim of this study was to assess the application of the TDM in a mail survey of Japanese dentists.

\section{Methods \\ Subjects}

The questionnaire was mailed to all 482 dentist members on Okayama Medical and Dental Practitioner's Association list. Out of 482 questionnaires sent out, four dentists were excluded because they had closed their office due to sickness or had shared replying survey with a spouse dentist. The final survey population was 478 dentists. Potential subjects were informed in the cover letter that participation in the study was voluntary and that individual responses would be confidential.

\section{Questionnaire development}

A nine-page, 27- item questionnaire was designed in English using questions derived from earlier surveys. It covered four categories: 1) dentist job satisfaction, 2) physical practice, 3) dentist and 4) patient characteristics. Instrumentation was translated from English to Japanese by a native speaker, and then back-translated by another native speaker to ensure comparability to the original English form (see Figure 1). The questionnaire booklet was organized so that easier and less personal questions were asked initially and more difficult or personal questions were asked at the end of the questionnaire. The questionnaire was pretested among the alumni practicing out of Okayama prefecture before use. The questionnaire was formatted into a $182 \times 257 \mathrm{~mm}$ booklet style to make it appear easier and less time-consuming to complete. 


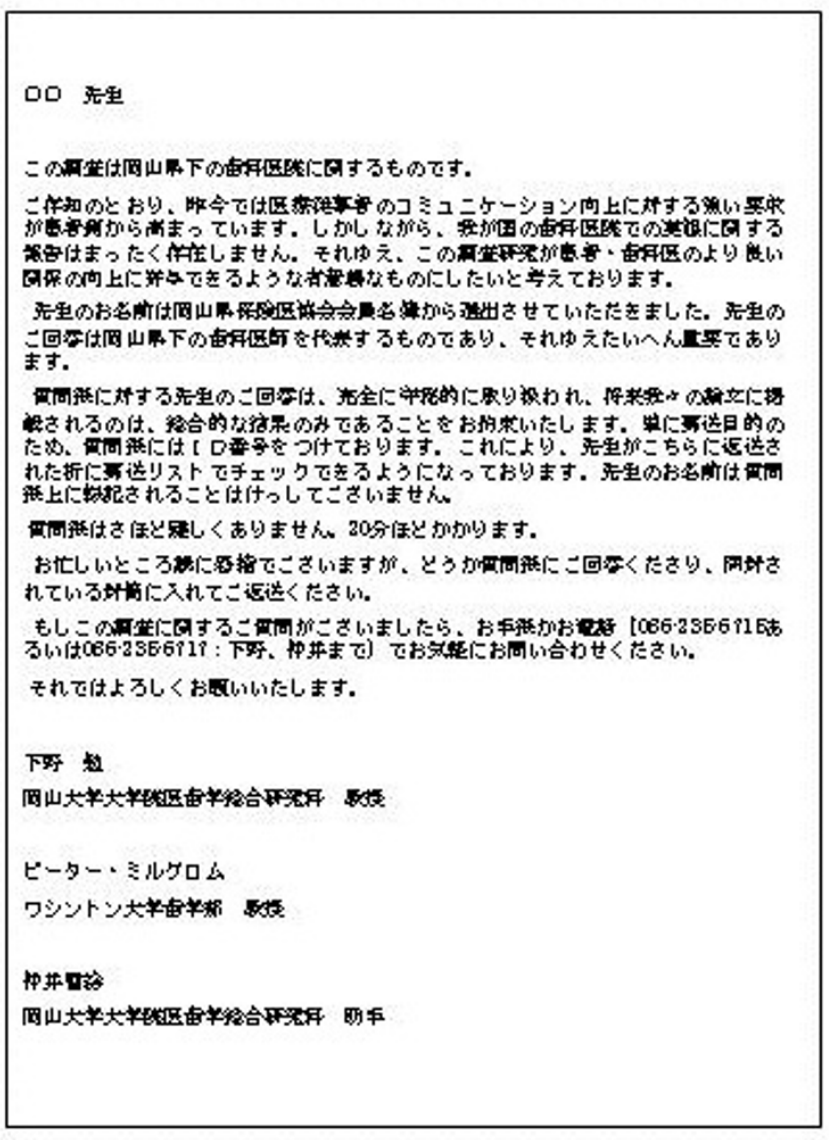

Dear Dr.00

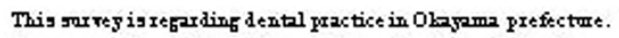

As gon mag bow, increasing nomber of patients defille better commonication between health care providers and patients. Howerer, there is nothing publishel abont dentel practice in Japan. This sorres, therefore, wo nd contribute to 2 more poritive relationabip betoreen dental practitioners and patienty.

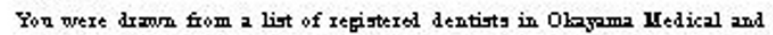
Dentel Fractitioner's Association. Yon reJonse wo nd Iepresent the dentists

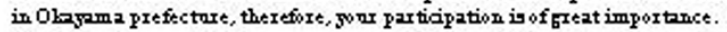

We will make sore that gow re Toons will be treated confidentially, and only composite re slt will be in onr paper. The identifiestion nomber in the

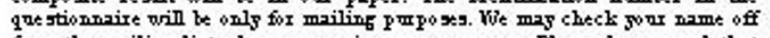

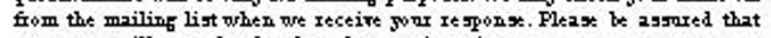
son name will neter be placed on the que stionnaire.

The que stionarire is not diffic nlt. It sho nld take le gs than 20 minntes.

We wonld troly appreciate son taking time to complete the que stionoaire ont of gour bnes xhed vle and returing it in the entelope provides.

We wo did be ters happs to angrex ang que stions jon mag bate abont this

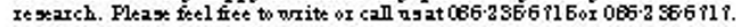

Thank gon in ad rance for son asritance.

Sincerely.

Trutomn shimono

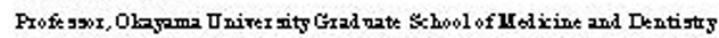

Peter Irilfrom

Froft s5or, University of Wizhington Shool of Dentists

Indit Nali

Asristant Frofessor, Ohagama Uriver rity Grad nate shool of Itediaine and Dentisty

\section{Figure 3}

Initial letter sent in the first mailing.

\section{Procedures}

The Okayama Medical and Dental Practitioner's Association agreed to participate and endorse the study.

The procedures followed were generally those recommended by Jussaume and Yamada [12] who had previously adapted the TDM to Japan. In designing the letters, a strong emphasis was placed on three essential features of the TDM. First, respondents were told how their names were selected, that their responses would represent those of many other Japanese dentists, and that their participation was invaluable. Second, the confidentiality of the survey was emphasized and participants were promised that their names would never be placed on the questionnaire. Finally, as an incentive for participation, a decision was made with the Association that respondents would be offered a report of the results of this study. No personal incentive was included in the survey because Japanese cul- ture values service to the group rather than the individual [12].

Approximately one week before the first mailing of the questionnaire, an advance letter including the Association endorsement was sent to all the dentists introducing the researchers and explaining the importance of the study (see Figure 2). The letters were not personalized and not individually signed. The letter noted that the participant would receive the questionnaire in a couple of days. The envelopes were personally addressed and stamped. In the first questionnaire mailing, the participants received a letter again explaining the importance of the study and assuring confidentiality (see Figure 3 ), the questionnaire booklet, and a stamped self addressed return envelope. Identification number markers were used on questionnaires so that respondents could be checked off the mailing list. A follow-up postcard (see Figure 4), encouraging 


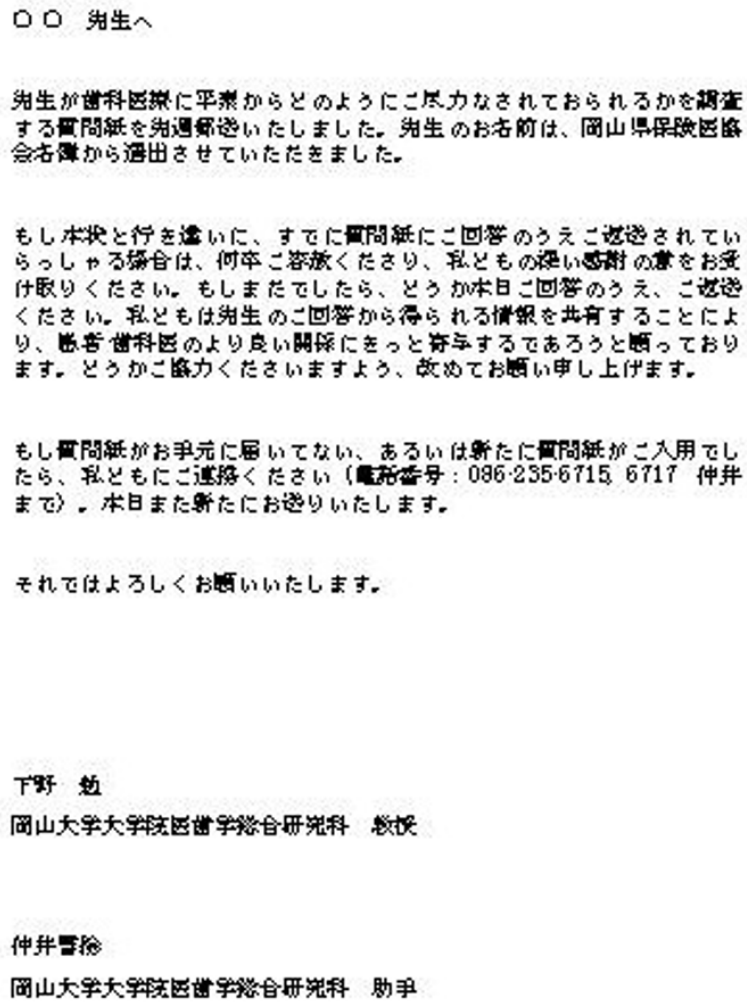

\section{Figure 4}

Follow-up card.
Dear Dr.0 o

I a st ueek, a questionsaire explocing how you are making an eftort to deliver dental servioe ua s mailed to you. You uere dra un from a lis of re gistered dentists in Olayama Medical and Dental Practitioner's Association.

If you have already ompleted the questionuaire and returned it to us, please excuse us and accept our aincere gratitude. If you have not, please do so today. Yie aurely believe your effort to share your information about your practioe uould contribute to a more positive rela tonship between practitioners and patient $s$.

If the que tionsaire uas not mailed to you or jou need another opy, plea 2 feel free to call us at $096 \cdot 235 \cdot 6715$ or $096 \cdot 235 \cdot 6717$. We woll mail another one to you.

Thank you for your a saistance.

Sircerely,

T sutomu इhimoro

Professor, Olayama Univeraity Graduate school of Medicine and Dentistry

Yulke Nakai

Assistant Professor, Olayama University Gradua te School of Medicine and Dentiatry participation, was sent about one week later. Three weeks after the first mailing, a replacement questionnaire, a stamped return envelope and a cover letter (see Figure 5) were sent to any dentists who had not responded. Dentists who did not respond within six weeks after the original mailing received a cover letter (see Figure 6), a second replacement questionnaire, and a stamped self addressed return envelope.

Japanese standard number 3 size $(235 \times 120 \mathrm{~mm})$ envelopes of an light yellow green color were used. Addresses were written on envelopes from left to right in the manner of most Japanese business correspondence.

\section{Data handling and analysis}

The data from questionnaires received within four months of the first mailing were entered into a database in Excel 2000 (Microsoft), and were checked for accuracy. Data management and analyses were conducted using SPSS version 11.5.
A two-pronged strategy was used to assess bias. First, age and gender of respondents and non-respondents, provided by the association list, were compared. Second, we compared study variables for early and late respondents. Respondents to the first mailing or the one-week followup postcard were defined as early responders; others who responded were late responders. Study variables included age, gender, years in practice, practice satisfaction, practice status, practice location, patient number seen per day, having postgraduate training, total hours of continuing dental education taken for the past 12 months, employment status (owner vs. non-owner), number of practice locations, yearly gross income before any expenses or taxes. T-tests, Fisher's exact test and Chi-square analyses were used to compare differences between the groups to assess respondent representativeness. 


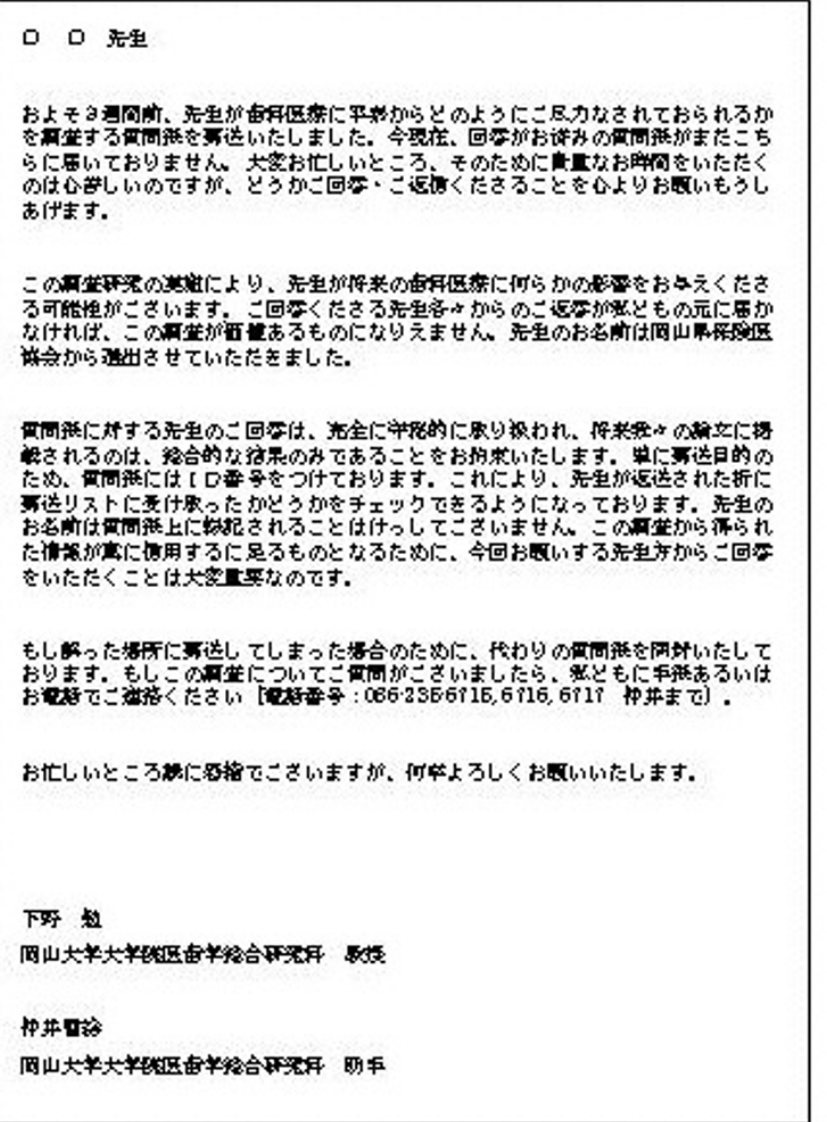

Figure 5

Second letter sent in the second mailing.

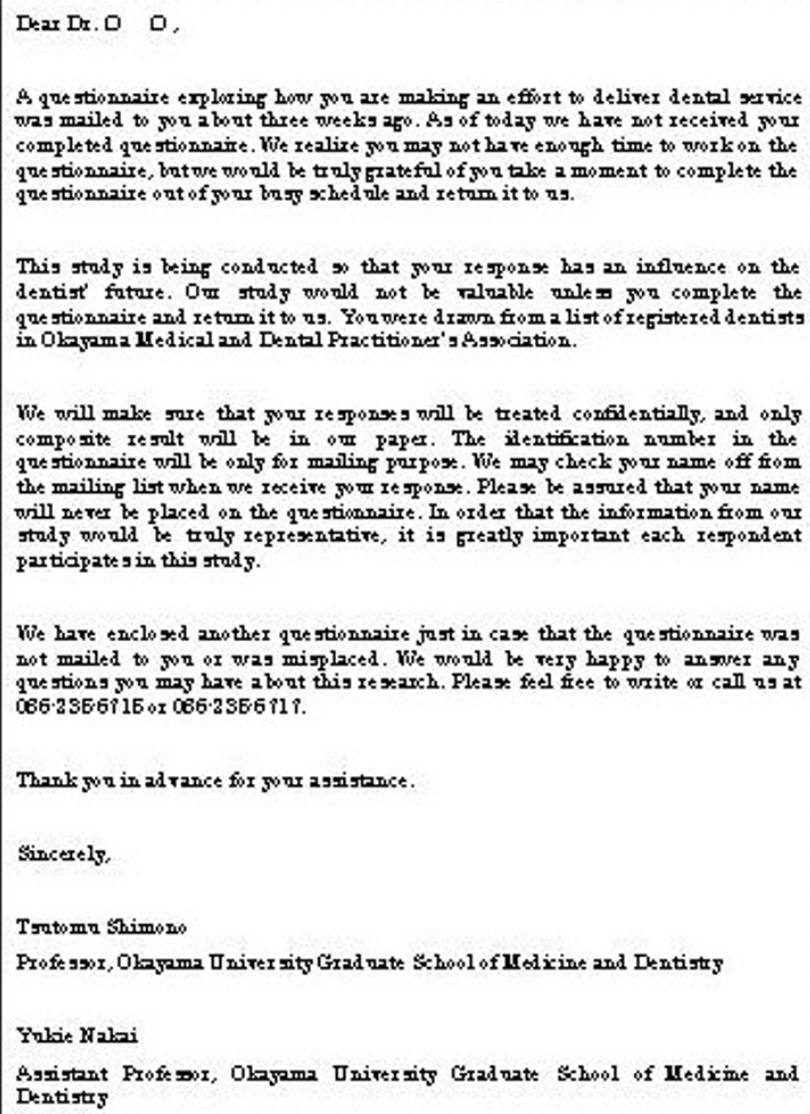
was mailed to jon a bont three wetks a5o. As of tod 25 wre hate not receired jour completed que stionarire. We realixe jog mag not hare eno ugh time to work on the

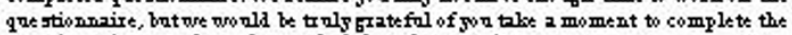
que stionazire ont of goor bosy sched nle and retom it to ng.

This stody is being conducted 9 that gonx regponst has an influence on the

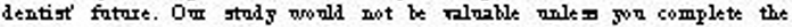

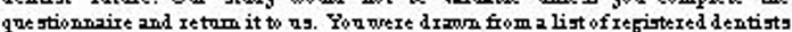
que ghonazire and retom it to ng. Yon were dramn from 2 li

We will make gore that gonx re Joures will be treated confilentially, and only composite Ie solt will be in ox paper. The ilentification nomber in the

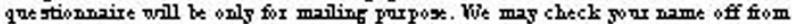

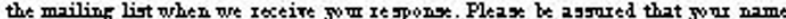
will mere be placed on the que stion will nerex be placed on the que stionaire. In order that the information from onf partidipates in this stady.

We hate enclosed another questionmaire just in cas that the questionnaire was not mailed to gon or was migplaced. We wo nld be rers bapp 5 to angrex ang que stions gon mas have 2 bont this re seach. Ple2x feel fiet to write or call ng 2 t 066.2SE6i16 or 066.2SE6 11?.

Thank gor in ad rance for $500 x$ agristace.

Sincerely,

Trotomn Shimono

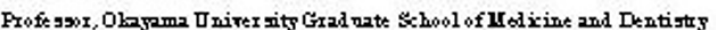

Yrobie Mabi

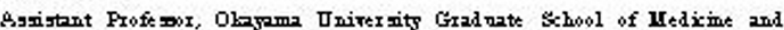
Dentistry

\section{Results}

\section{Response rate}

The overall response rate was $46.7 \%$ (223/478). The cumulative response rates by each follow-up mailing are shown in Table 1. Ten dentists declined to participate. The primary reason given for refusal was that the dentist was not comfortable in answering personal questions.

\section{Respondent representativeness}

Respondents did not differ from non-respondents for the gender and age, nor were there differences between early and late responders for any of the 12 of variables that were compared except that the late responders have taken less hours of continuing dental education during the past 12 months ( 17.5 vs. 29.2 hours; $\mathrm{t}=1.95, \mathrm{p}=0.05$ ) (Table 2 ). There was a trend for late responders to be more likely to have received postgraduate training (27.3\% vs. $16.3 \%$; Fisher's exact test, $\mathrm{p}=0.08$ )

\section{Discussion}

The TDM, as generally adapted by Jussaume and Yamada [12], was used in a survey of Japanese dentists. Previously Jussaume and Yamada obtained nearly identical response rates when they surveyed the general public in Japan (55.6\%) and the U.S. (57.5\%) using this method. The application of the TDM in this survey of dental practice produced a lower response rate $(46.6 \%)$ than expected but with little response bias. The results of a low response rate $(43 \%)$ without non-response bias was previously reported in the US dentist population [13] although other studies using this method have produced higher response rates. Dentists can be considered to have sufficiently similar education, income, and interest to be considered a homogeneous group. If there is little difference between the respondents and non-respondents, a smaller percentage of return might be acceptable. Parashos and colleagues, who reported a dentist survey in Australia and New Zealand also using the TDM, found significant differences between early and late respondents in responses to 


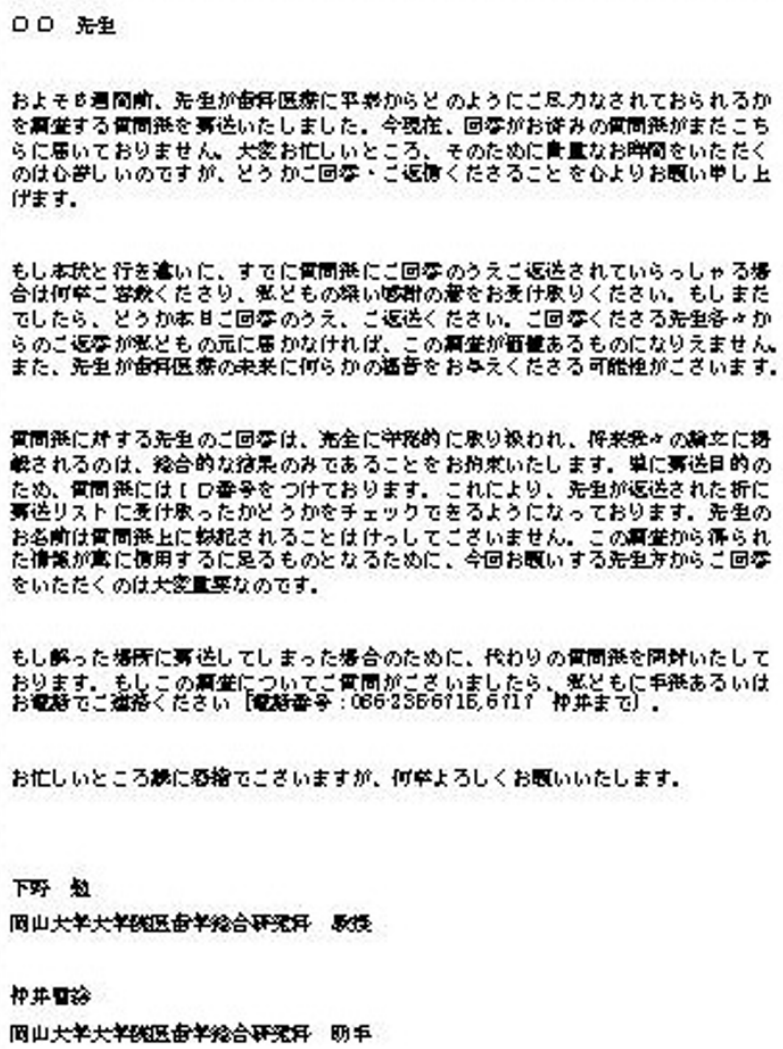

\section{Figure 6}

Third letter sent in the third mailing.

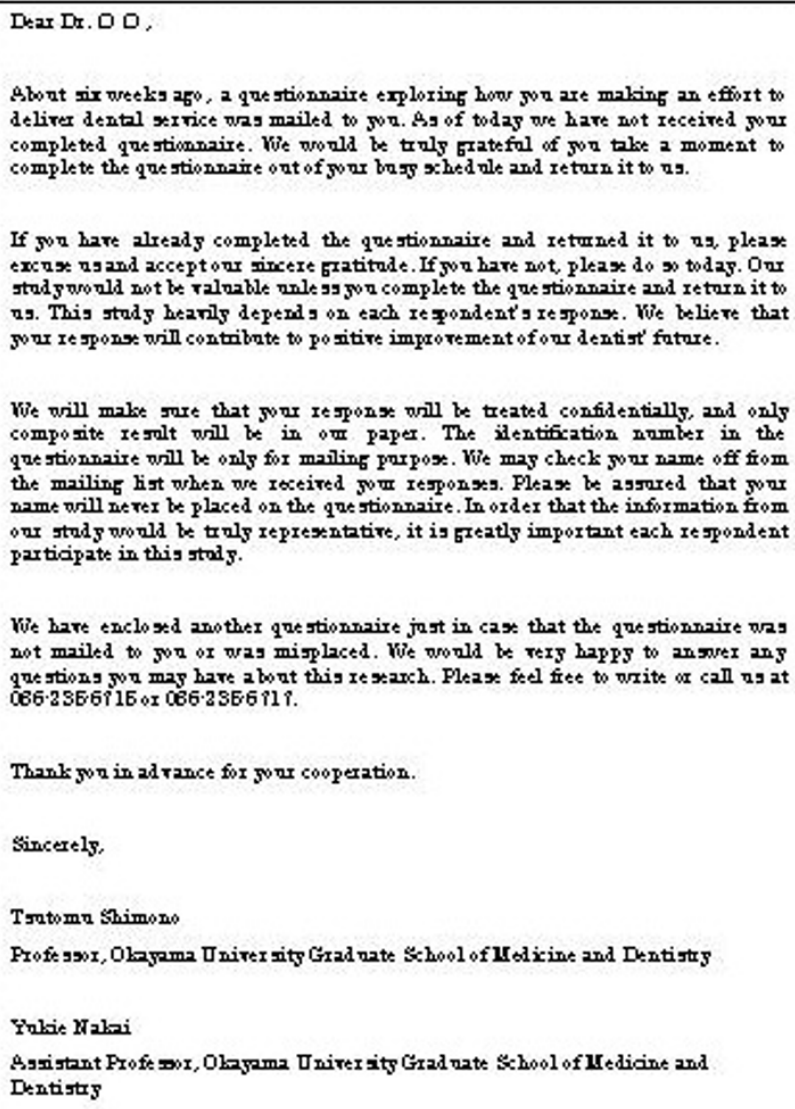

We will make sore that gour re Joons will be teated confidentially, and onls comporite resolt will be in oxr $P^{2}$ ex. The ilentification nomber in the que stionnaire will be only for mailing purpose. We mas check jonx name off firom the miling list when no recired

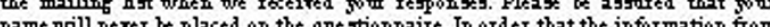
a

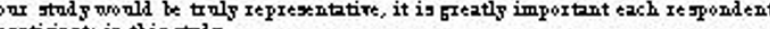
participate in this stails.

We hate enclosed another que stionarixe jost in case that the que stionnaire was not mailed to gon ox was migplaced. We woold be vexy happ to ansorex ang que stiong jon mas hate 2 bont this re search. Plezse feel fiet to write or call ng at Q66.23E6 16 $0106 \cdot 236611$.

Thank jon in ad rance for $300 \mathrm{n}$ cooperation.

Sincerely.

Trotomn shimono

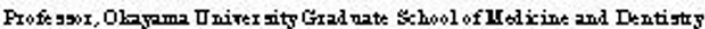

Yokie Mali

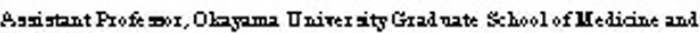

Dentistrs

Table I: Cumulative response rate to Japanese dental questionnaire using the TDM

\begin{tabular}{lllll}
\hline & I st Mailing & Follow-up Card & 2nd Mailing & 3rd Mailing \\
\hline Response rate & $18.0 \%$ & $21.2 \%$ & $10.7 \%$ & $7.6 \%$ \\
& $(86 / 478)$ & $(83 / 392)$ & $(33 / 309)$ & $(21 / 276)$ \\
Cumulative & & $35.4 \%$ & $42.3 \%$ & $46.7 \%$ \\
response rate & & $(169 / 478)$ & $(202 / 478)$ & $(223 / 478)$
\end{tabular}

a specific survey question of topical interest despite the absence of differences in the demographic data [14]. They emphasize the importance of using methods to achieve a high response rate to overcome such bias.

The lower than anticipated response rate of this study may have resulted from our failure to follow all aspects of the TDM fully. One of the differences found in procedures between Jussaume's [12] and this study was that neither
Inkan (personal seal) nor signature was used to the letter in this study. Jussaume said that it could convey to the respondent the importance which researchers placed on the project. The other difference was that the letter was not written in longhand in this study. Japanese respondents are hypothesized to react more positively to a survey seeing the effort taken to write out their names in longhand. Japanese dentists may also be more reluctant to answer the questions that they feel too personal. Ten dentists had 
Table 2: Responses on study variable for early/late responders

\begin{tabular}{|c|c|c|c|c|}
\hline Variables & $\mathbf{N}$ & Early responders & Late Responders & $\mathbf{p}$ \\
\hline Mean age (SD) & 223 & $45.6(9.8)$ & $45.6(10.9)$ & NS \\
\hline$\%$ female & 223 & 9.5 & 7.4 & NS \\
\hline Mean months in practice (SD) & 220 & $163(117)$ & $172(129)$ & NS \\
\hline Practice satisfaction (\% dissatisfied) & 215 & 24.7 & 22.6 & NS \\
\hline Busyness (\%not busy enough) & 220 & 28.7 & 30.2 & NS \\
\hline Practice location (\% patients from rural areas) & 212 & 28.7 & 29.2 & NS \\
\hline Patient visits/day (mean, SD) & 212 & $34.5(25.6)$ & $32.2(26.2)$ & NS \\
\hline Postgraduate training (\%no) & 215 & 25.5 & 15.1 & 0.08 \\
\hline Total hrs CDE/I 2 mos (Mean, SD) & 197 & $29.2(58.7)$ & $17.5(24.9)$ & 0.05 \\
\hline Employment status (\% non owner) & 219 & 15.7 & 13.2 & NS \\
\hline$>$ I practice location & 214 & 4.9 & 7.8 & NS \\
\hline Annual gross income before expense/taxes (\% less than $¥ 30,000,000$ & 194 & 23.0 & 34.8 & NS \\
\hline Year of graduation (mean, SD) & 212 & 1981 (10.7) & 1981 (11.7) & NS \\
\hline
\end{tabular}

refused to participate in this study due to such reasons. One of the authors asked the primary reasons why they didn't participate to another five dentists. Two of these five dentists said the questions were too personal and that there were too many questions to answer. One dentist said that he didn't want his practice to be compared with others. Two said that topic was not interesting enough to make them want to participate.

The response rate was, however, much greater than that of another unpublished survey of Japanese dentists that achieved a $10 \%$ response rate. The follow-up contact and repeated mailing to non-respondents increased our sample size by more than a quarter $(28.7 \%)$. Before using the postcard reminder, the response rate was one-third of the final rate, suggesting that follow-up contact is critical to bolstering mail survey response rates. This is consistent with research indicating that follow-up contact has the most positive effect on return rates [11,15-17].

Our results are encouraging, and demonstrate the feasibility of using TDM to study a population of Japanese dentists.

\section{Conclusion}

The application of TDM in this survey of Japanese dentists produced lower rates of response than expected from previous Japanese and US studies with little response bias.

\section{List of abbreviations \\ TDM Total Design Method}

\section{Competing interests}

The author(s) declare that they have no competing interests.

\section{Authors' contributions}

YN participated in the design of the study, made the instruments (translated English version to Japanese), negotiated with Okayama Medical and Dental Practitioner's Association to be given endorsement, collected the data, performed the statistical analyses, and drafted the manuscript. PM participated in the design of the study and in writing the manuscript. TY participated in the design of the study and developed the English version of the instruments for this paper. CI collected the data and performed the statistical analyses. TS participated in the design of the study. All authors read and approved the final manuscript.

\section{Acknowledgements}

The authors wish to thank all participating dentists who responded our mail survey and Okayama Medical and Dental Practitioner's Association who agreed to participate in our mail survey. The study was supported in part by funds from Okayama University.

\section{References}

I. Hara J, Umino M: Shakai Chosa Enshu Tokyo: Tokyo Daigaku Shuppan Kai; 1984. in Japanese

2. Igaki S: Shakai Chosa Nyumon Kyoto: Mineruba Shobo; 1968. in Japanese

3. Kobayashi S: Shakai Chosa Ron Tokyo: Bunshindo; 198I. in Japanese

4. Ota $\mathrm{H}$, Tanimoto $\mathrm{S}$, Takayanagi $\mathrm{K}$, Kimura $\mathrm{T}$, Oida $\mathrm{T}$ : A preliminary study on the knowledge and attitudes of physicians at two university hospitals towards the medical insurance system of Japan. Tohoku J Exp Med 2000, 190:143-155.

5. Konno R, Sato S, Yajima A: A questionnaire survey on current surgical procedures for endometrial cancer in Japan. Tohoku J Exp Med 2000, 190:193-203.

6. Sakakihara Y: Ethical attitudes of Japanese physicians regarding life-sustaining treatment for children with severe neurological disabilities. Brain Dev 2000, 22: | |3- | I7.

7. Funatsu H, Hori S: Present status of ophthalmological care for diabetic patients in Japan. Jpn J Ophthalmol 2000, 44:75-8I.

8. Oshima A, Higuchi T, Fujiwara Y, lida M, Iwanami A, Kanba S, Motohashi N, Uchitomi Y, Yamada K, Yamawaki S: Questionnaire survey on the prescribing practice of Japanese psychiatrists for mood disorders. Psychiatry Clin Neurosci 1999, 53(Suppl):S67-72. 
9. Dillman DA: Mail and telephone surveys: The Total Design Method New York: John Wiley \& Son; 1978.

10. Locker D, Grushka M: Response trends and nonresponse bias in a mail survey of oral and facial pain. J Public Health Dent 1988, 48:20-25.

II. Fiset L, Milgrom P, Tarnal J: Dentists' response to financial incentives in a mail survey of malpractice liability experience. J Public Health Dent 1994, 54:68-72.

12. Jussaume RA, Yamada Y: A comparison of the viability of mail surveys in Japan and the United States. Public Opin Q 1990, 54:219-228

13. Hovland EJ, Romberg E, Moreland EF: Nonresponse bias to mail survey questionnaires within in a professional population. J Dent Educ 1980, 44:270-274.

14. Parashos P, Morgan MV, Messer HH: Response rate and nonresponse bias in a questionnaire survey of dentists. Community Dent Oral Epidemiol 2005, 33:9-16.

15. Fox RJ, Crask MR, Kim J: Mail survey response rate: $\mathbf{A}$ metaanalysis of selected techniques for inducing response. Public Opin Q 1988, 52:467-491.

16. Weathers PL, Furlong MJ, Solorzano D: Mail survey research in counseling psychology: Current practices and suggested guidelines. J Couns Psychol 1993, 40:238-244.

17. Gore-Felton C, Koopman C, Bridges E, Thoresen C, Spiegel D: An example of maximizing survey return rates. Methodological issues for health professionals. Eval Health Prof 2002, 25: I52-I68.

\section{Pre-publication history}

The pre-publication history for this paper can be accessed here:

http://www.biomedcentral.com/1471-2288/5/27/prepub

Publish with Biomed Central and every scientist can read your work free of charge

"BioMed Central will be the most significant development for disseminating the results of biomedical research in our lifetime. "

Sir Paul Nurse, Cancer Research UK

Your research papers will be:

- available free of charge to the entire biomedical community

- peer reviewed and published immediately upon acceptance

- cited in PubMed and archived on PubMed Central

- yours - you keep the copyright 